\title{
Resenha
}

\section{Energia e Matéria: Da Fundamentação Conceitual às Aplicações Tecnológicas}

(Energy and Matter: From the Conceptual Grounds to the Technological Applications)

\author{
Paulo M.C. Oliveira ${ }^{\text {m2 }}$ \\ ${ }^{1}$ Instituto de Física, Universidade Federal Fluminense, Niterói, RJ, Brasil \\ ${ }^{2}$ Instituto Mercosul de Estudos Avançados, Universidade Federal da Integração Latino Americana, Foz do Iguaçu, PR, \\ Brasil \\ Recebido em 7/7/2015; Aceito em 9/7/2015; Publicado em 12/12/2015
}

Resenha do livro Energia e Matéria: Da Fundamentação Conceitual às Aplicações Tecnológicas, organizado por Carlos Alberto dos Santos, editora da Livraria da Física, São Paulo, 2015.

Palavras-chave: energia, matéria, interdisciplinaridade.

Book review of Energy and Matter: From the Conceptual Grounds to the Technological Applications, organized by Carlos Alberto dos Santos, Livraria da Física, São Paulo, 2015.

Keywords: energy, matter, interdisciplinarity.

A multidisciplinaridade é uma realidade moderna que precisa ser devidamente tratada no ensino fundamental, médio, técnico e universitário, com urgência. A resistência inercial a este fato no meio acadêmico nacional tem sido grande. No entanto, a tradicional divisão da ciência em diferentes disciplinas foi elaborada com base na ciência que se estudava há mais de dois séculos. A Natureza obviamente não leva em conta esta divisão artificial. De lá para cá, inserções de assuntos tradicionalmente pertencentes a uma destas disciplinas em outra ocorreram cada vez com maior frequência. O cenário hoje é próximo do anacronismo. É necessário que se leve isto em conta na elaboração das grades curriculares. Cumpre alertar, entretanto, que não se trata de substituir as tradicionais disciplinas curriculares, divididas em compartimentos estanques, por outras ditas "interdisciplinares", "multidisciplinares", "transdisciplinares", termos muito em moda nas lides pedagógicas do país, mas que até então têm refletido apenas um relaxamento dos conteúdos das várias disciplinas tradicionais a englobar na "nova" disciplina curricular apenas noções superficiais e insuficientes destes diversos conteúdos. Trata-se, sim, de abrir o leque de cada disciplina tradicional para as citadas inserções que ela recebeu de outras, suas aplicações nestas outras. Este livro é uma das primeiras iniciativas no sentido de cumprir esta necessidade. Apresenta textos de autores de várias origens acadêmicas, sobre temas gerais, de

\footnotetext{
${ }^{1}$ E-mail: oliveira.paulomurilo@gmail.com.

formas variadas. Comentarei a seguir alguns aspectos destes textos.

Energia é uma palavra usada em diferentes contextos. Possui significados díspares, desde os precisos conceitos científicos até os esotéricos conceitos do tipo "energia positiva" ou "negativa" emanada por uma pessoa. Essa diversidade cria confusão na mente do cidadão comum. O consequente uso inadequado do termo é extremamente comum. Por exemplo, usa-se no cotidiano o termo "produção de energia", e ao mesmo tempo a boa ciência afirma que a energia do universo se conserva, jamais se perde nem é criada. Neste livro, os significados estritamente científicos das várias formas como a energia pode se apresentar são descritos de maneira coloquial, com o objetivo de mitigar a citada confusão. O termo "produção de energia" é colocado no seu devido significado cientificamente preciso da transformação de uma forma de energia em outra. Outros termos relacionados, como temperatura, calor e entropia também são tratados, assim como suas diferenças e as relações entre eles. Um objeto estará quente se sua temperatura for alta. Mas esse mesmo objeto não possui calor, que é energia em transição. Calor foi transferido para o objeto ao esquentá-lo, não é uma propriedade do objeto, uma variável de estado do objeto. Sua temperatura, sim, era baixa e ficou alta. Entropia é outra variável de estado. Ao contrário da energia, não se conserva, sempre aumenta num sistema isolado 
(como o universo). Toda vez que energia concentrada é espalhada, o valor da entropia aumenta. Portanto, políticas conservacionistas se aplicam à entropia, não à energia. Conservar, no sentido ecológico, é preservar baixa a entropia.

Aspectos tecnológicos, como o funcionamento de usinas nucleares de fissão (em uso) ou de fusão (em fase experimental) para a "produção" de energia elétrica, também são descritos. Fora estes dois casos, toda a energia que usamos (hidrelétrica, termelétrica, eólica, veicular, etc) vem da radiação solar que incide na superfície da Terra, ou incidiu no passado. A conversão natural ou artificial desta energia de radiação em outras formas utilizadas pela humanidade também é descrita, juntamente com suas implicações tecnológicas, sociais e ecológicas.

Os vários combustíveis usados em motores e geradores têm o importante inconveniente de liberar na atmosfera gases que contêm carbono, contribuindo assim para o conhecido efeito estufa e o consequente aquecimento global, além da poluição direta. Em grandes usinas, fixas no solo, pode-se capturar os gases produzidos na combustão, filtrá-los e armazenar os resíduos nocivos em abrigos subterrâneos ou submarinos. Em veículos, no entanto, a captura é inviável. O uso de hidrogênio como combustível alternativo não apresenta este inconveniente, porque só produz vapor d'água. Entretanto, não existem reservas minerais de hidrogênio gasoso na Terra, como carvão e petróleo. Mas pode-se produzir hidrogênio em uma usina fixa no solo que não emite gases de efeito estufa, e usá-lo posteriormente como combustível veicular. Há uma série de tecnologias, já disponíveis algumas, outras na fase de pesquisas, para o transporte e armazenamento de hidrogênio, bem como o inerente problema de segurança em todo o processo. O funcionamento das chamadas células de combustível, dispositivos químicos que transformam diretamente o combustível em eletricidade, é descrito. Estes dispositivos cumprem o mesmo papel que as baterias elétricas em suas diversas aplicações. Além de combustível limpo para veículos e algumas instalações fixas no solo ou no espaço, outros usos de hidrogênio também são apresentados.

Pouca ciência foi produzida no Brasil, por brasileiros, antes do Século XX. Este fato contribuiu efetivamente para o nosso atraso científico atual, relativo a outras nações. Como agravante, muito pouco da pouca ciência aqui produzida é conhecida pelo grande público, e mesmo no meio científico. A falta de divulgação, entre outros fatores, tem como consequência o baixíssimo prestígio que a ciência e a atividade científica em geral desfrutam na nossa população. Não é portanto surpresa que mesmo as elites dirigentes não compreendem e não percebem a necessidade do desenvolvimento científico nacional, como suporte do desenvolvimento econômico e social. Há pouco mais de uma década, um ministro da economia brasileiro chegou a comentar num discurso que o investimento em ciência e tecnologia não é importante, porque podemos comprar o que necessitamos.

Esta situação precisa ser revertida. Para tanto, a divulgação para o grande público da história da ciência brasileira é fundamental. No caso da Química antes do Século XX, o livro preenche este objetivo. Estão lá, descritos de forma coloquial, os pioneiros feitos científicos brasileiros e seus heroicos personagens nesta área. Além disto, o texto é um incentivo para que esse trabalho seja repetido em outras áreas científicas.

Metade da crosta terrestre é composta pelo elemento oxigênio, outro quarto, silício. O carbono, no entanto, que corresponde a mais da metade do material encontrado num ser vivo, responde por menos de $1 \%$ da crosta terrestre. Os químicos dividem sua disciplina em orgânica, a que trata dos compostos do carbono, e a inorgânica, que trata do resto. Divisão esta aparentemente desproporcional se considerada a distribuição dos elementos na crosta terrestre em que vivemos, mas que se explica pela complexidade muito maior dos compostos do carbono e sua importância para a vida.

Os compostos orgânicos são cadeias de carbono, ao longo das quais aparecem diferentes radicais que contêm hidrogênio, nitrogênio, oxigênio, fósforo, ferro, etc. O número de átomos de carbono na cadeia, o tipo de ligação entre carbonos vizinhos (simples, dupla, etc) e os citados radicais que aparecem num dado composto determinam sua nomenclatura científica. Tal nomenclatura segue uma regra muito bem definida que permite o conhecimento da estrutura do composto através de seu nome. Portanto, esta convenção internacional de nomenclatura é muito útil. Os fármacos, por exemplo, recebem denominação de acordo com o seu princípio ativo, o que facilita a identificação da estrutura química da molécula responsável pela sua função terapêutica e a classificação de fármacos equivalentes ou semelhantes numa mesma classe. São muitos fármacos e poucas classes. No livro são descritas as regras convencionadas de nomenclatura dos compostos orgânicos.

A tabela periódica é normalmente apresentada aos estudantes sem maiores explicações. No entanto, ela reflete a distribuição dos elétrons atômicos que orbitam em torno do núcleo. Não é uma distribuição contínua, ao contrário, os elétrons se distribuem em diferentes estados, cada um com sua energia própria e podendo abrigar apenas um elétron. Por outro lado, a situação estável de um átomo corresponde à menor energia total possível, a soma das energias de todos os elétrons. Não é possível que todos ocupem o mesmo estado de menor energia. Um elétron ocupa o estado de menor energia, os seguintes são obrigados a se ajeitar em estados de maior energia. É como um edifício em que cada apartamento pode ser ocupado por um único indivíduo. Para minimizar o esforço de subir escadas, os apartamentos do primeiro andar são ocupados, depois os do segundo andar, etc. Qual será o último andar ocupado? Depende do número total de indivíduos. 
Este último andar atingido está todo ocupado, ou apenas parcialmente? As ligações químicas entre átomos correspondem ao compartilhamento de alguns de seus elétrons, visitas de alguns habitantes de um edifício aos apartamentos vazios do edifício vizinho. Naturalmente, estas visitas não podem ser aos andares mais baixos do edifício visitado, que estão totalmente ocupados. Há vagas no último andar ocupado? Se houver, as visitas são energeticamente facilitadas. Se não houver vagas no último andar ocupado, as visitas teriam que ser feitas ao próximo andar superior, o que dificultaria a ligação química. Portanto, a afinidade de átomos se ligarem quimicamente e formar moléculas depende da ocupação por elétrons de seus estados mais energéticos, dos graus de ocupação de seus últimos andares. Os gases nobres, por exemplo, são quimicamente inertes porque seus últimos andares estão completamente ocupados.

No livro é descrita a estrutura dos edifícios (na imagem que fiz acima), quantos apartamentos há em cada andar. Compreende-se então como os elementos químicos são classificados na tabela periódica segundo o número de elétrons de cada átomo. Como elementos de cada classe têm ou não afinidade química com elementos de outra classe. A estrutura dos edifícios, quantos apartamentos há em cada andar, é conhecida graças à Mecânica Quântica, a espetacular e surpreendente teoria científica desenvolvida no início do Século XX. A história deste desenvolvimento, seus conceitos fundamentais e seus personagens também são descritos.

Todos os espetaculares aparelhos eletrônicos que mudaram a vida dos seres humanos a partir do início do século passado são fruto da manipulação de materiais semicondutores, sobretudo o silício. Um século antes, fenômenos notáveis já haviam sido observados nestes materiais, como o controle da corrente elétrica que podem ou não conduzir através da incidência de luz. Observados sim, mas misteriosos e não explicados até a década de 30, quando a recém elaborada teoria da Mecânica Quântica pode ser aplicada à condução de eletricidade nos sólidos. Em particular, melhor que o silício puro, amostras de silício contaminadas (ou dopadas, no jargão da eletrônica) com boro (tipo-P) ou com fósforo (tipo-N) possibilitaram as inúmeras aplicações tecnológicas que diferenciam enormemente nossas vidas das de nossos avós: computadores, televisão, laser, sistemas de comunicação à distância, etc. A simples junção de duas minúsculas pastilhas de silício, de um lado o tipo-P e de outro o tipo-N, com um terminal metálico de entrada ou saída de corrente em cada uma, cria um dispositivo chamado diodo que permite a passagem de corrente elétrica apenas num sentido, a chamada junção PN. Sua descoberta é um exemplo de serendipidade, que significa descoberta ao acaso. O mesmo dispositivo devidamente preparado e polido, quando atravessado por uma corrente externa, cria um feixe de luz laser. Com um pouco mais de sofisticação, cria-se outro dispositivo chamado transistor, com uma terceira camada semicondutora intermediária entre $\mathrm{P}$ e $\mathrm{N}$ ligada a um terceiro terminal metálico ao qual se aplica ou não uma minúscula voltagem para controlar a corrente elétrica que passa ou não entre os outros dois terminais. Assim, o código SIM ou NÃO da lógica binária de qualquer processamento computacional é traduzido na eletrônica pela passagem ou não de corrente elétrica num transistor. Na chamada microeletrônica, tais dispositivos têm dimensões da ordem de micrômetros (um milionésimo do metro, onde cabem cerca de dez mil átomos em fila). Na nanoeletrônica que ora se inicia, são atingidas as dimensões de nanômetros (um bilionésimo do metro, dez átomos em fila). Um transistor com seus diversos componentes, terá dimensões, suponhamos, dez vezes maiores. Portanto, um "chip" com dimensões superficiais de $1 \mathrm{~mm}$ x $1 \mathrm{~mm}$ poderá num futuro próximo abrigar o inimaginável número de dez bilhões de transistores ou outros elementos eletrônicos! Para efeitos de comparação, nosso cérebro é muito maior, mas abriga o mesmo número de neurônios, dez bilhões.

Outros dispositivos modernos da nanotecnologia, como os microscópios de tunelamento capazes de "enxergar" detalhes na escala atômica, a spintrônica em que os elétrons portadores de corrente elétrica são manipulados não através de campos elétricos como na eletrônica tradicional, mas por meio de suas propriedades magnéticas (o spin), são também descritos no texto.

É imediato para qualquer humano, atualmente ou no passado, distinguir um ser vivo dos inanimados. Não é trivial, no entanto, comparar as características de um ser vivo com as de outro e classificá-los. Até três séculos atrás, essa classificação era feita exclusivamente com base nos aspectos morfológicos visíveis, na escala macroscópica. Nas comparações, usavam-se analogias entre a função de um órgão num dado ser vivo com o que se supunha ser o órgão equivalente de outro ser vivo. A coerência da criação divina era um critério fundamental: se uma criatura funciona de tal maneira, outra criada pelo mesmo ente divino deve funcionar da mesma maneira. Essas analogias pouco científicas levaram a muitos enganos na classificação dos seres vivos. Nesta época, o advento do microscópio permitiu a observação de células, na escala mesoscópica (abaixo do milímetro). E também de uma nova classe de seres vivos unicelulares, para os quais as analogias funcionais perdem o sentido. A partir do Século XX, microscópios mais potentes (primeiro ópticos, depois eletrônicos e atualmente os de varredura que permitem observações na escala atômica) e outros instrumentos sofisticados possibilitaram observar o interior das células. As analogias macroscópicas antes apenas supostas sob a hipótese da citada coerência divina, deixaram de ser suposições na escala molecular. Moléculas idênticas estão presentes nas células de diversos seres vivos distintos, cum- 
prindo as mesmas funções. Evidências de que todos os seres vivos do planeta têm a mesma origem se acumularam cada vez mais. A teoria de Lamarck, lançada em 1809, de que as diversas espécies biológicas atuais descendem de espécies ancestrais numa árvore de bifurcações (especiações) ganhou então credibilidade incontestável. Assim é a evolução das espécies. Esta árvore de bifurcações tem uma única origem comum (terrestre?), longínqua no tempo evolucionário, todos os seres vivos descendem do mesmo ancestral comum. Uma das inúmeras evidências deste fato é a existência de moléculas exclusivamente levógiras (moléculas que fazem a polarização da luz que as atravessa girar sempre num dado sentido) em todos os seres vivos. As mesmas moléculas podem ser encontradas no mundo inanimado, tanto levógiras quanto destrógiras (giro da polarização no sentido oposto). Porque, então, apenas as levógiras estão presentes nas células dos seres vivos? Resposta: porque o primeiro ancestral comum assim era, por acaso, e todos os outros seres vivos presentes e passados descendem dele. Algumas destas moléculas podem ser sintetizadas em laboratório, e como resultado metade delas serão levógiras e a outra metade destrógiras. A inobservância desta realidade já trouxe consequências desastrosas para a humanidade, no caso da talidomida. Trata-se de um medicamento lançado para a prevenção de enjoos de mulheres grávidas. A existência de moléculas destrógiras na talidomida sintética trouxe como consequência sérias deformações de milhões de fetos (futuras crianças e depois adultos) gerados por estas mães. A talidomida foi banida da medicina, mas apenas depois se descobriu a causa do problema. 